\title{
Many British parents say children not brushing teeth long enough
}

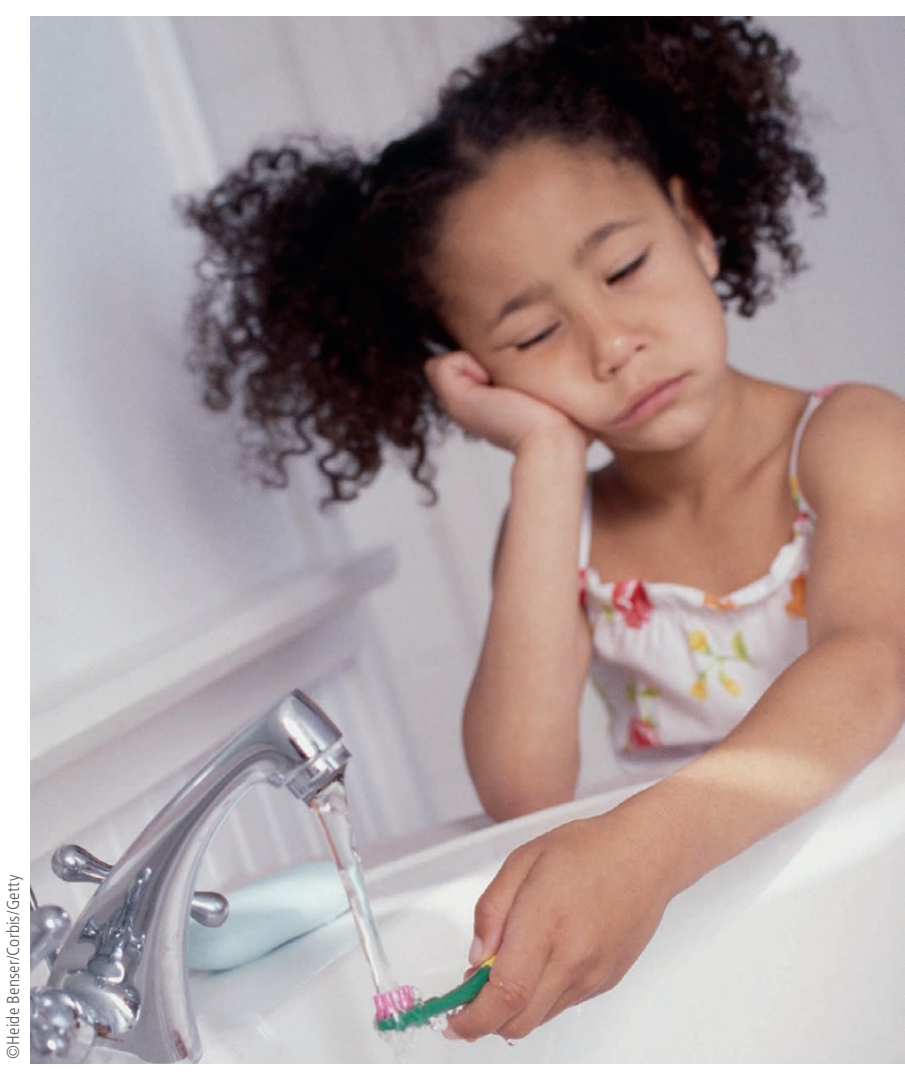

Nearly three in five British parents with children aged 3 to 12 say their children are not brushing their teeth for long enough, according to a recent survey.

The survey carried out by YouGov on behalf of the makers of Playbrush - an interactive smart toothbrush that encourages children to brush by turning brushing into a game - involved 1,000 parents with children aged under 18 and of the parents, 589 have children aged 3 to 12 .

The survey found that $58 \%$ of parents with children between the ages of 3 and 12 said their children did not brush their teeth for the twominute minimum recommended by the BDA for each brushing session.

A total of $40 \%$ of those asked stated their children did not brush longer than a minute, and $12 \%$ of parents said their children brushed for 30 seconds or less.

The survey was timed to coincide with the launch of the first electric Playbrush, the Playbrush Smart Sonic, on 31 August 2018, and provides insights into parental attitudes on children's tooth brushing habits.

Getting children to brush their teeth was a source of stress for many families, as the survey showed that $46 \%$ of parents agreed that they have worried about their child's teeth as a result of trying to get them to brush. Around a quarter (24\%) of parents said they had lost their temper while attempting to get their children to brush, while $71 \%$ felt that technology could be used to achieve better oral health among children alongside traditional tooth brushing methods.

The Playbrush Smart Sonic connects to an electric toothbrush and transforms it into a game controller, motivating children to brush regularly, longer, and with greater accuracy via an app which allows children to track progress on the games, and parents to monitor their child's tooth brushing habits and dental health. 